\title{
Effect of Water Hardness on Non-Communicable Diseases, Including Chronic Kidney Disease of Multifactorial Origin (CKDmfo/CKDuo)
}

\author{
Sunil J. Wimalawansa*
}

Cardio Metabolic Institute, Somerset, NJ, USA

"Corresponding author: Prof. Sunil J. Wimalawansa, MD, PhD MBA, DSc. Cardio metabolic Institute, New Jersey, U.S.A, E-mail: suniljw@hotmail.com

\begin{abstract}
Environmental pollution, including air and water contamination, causes or aggravates many acute and chronic human diseases. Although scientific literature prior to the last decade showed some associations between hardness/softness of water with cardiovascular diseases, recent data do not support this proposition. Previously postulated associations were derived from the data generated from observations and uncontrolled epidemiological and cohort studies; the results of which have not been confirmed. It was claimed that consumption of soft water increased cardiovascular diseases whereas hard water decreased them. Critical evaluation of recent data support neither of these claims. Recently, an association between drinking hard water (or ionicity) and chronic kidney disease of multifactorial origin (CKDmfo/CKDuo) has been proposed but disputed by others. CKDmfo/CKDuo is prevalent in dry-zonal, agriculture-based tropical countries, including Sri Lanka. Most regions affected by CKDmfo had hard water for centuries, but this disease has manifested only during the past few decades. However, during the past four decades, there had been several key changes in these agricultural regions, such as the increased use of agrochemicals associated with the green revolution, environmental pollution, and human behavioral changes including abandoning traditional agricultural methods and unhealthful food habits. Despite the absence of scientific data, few claim that CKDmfo is caused by the hypothetical complexes of pesticides, heavy metals, and hard water. Even if such complexes are formed, these components are insoluble in water and highly unlikely to be absorbed through the gastrointestinal tract. Apart from the well-known association of the consumption of hard water and chronic dehydration with urinary stones, there are no other scientifically established associations of water hardness with human diseases. Considering the pathophysiology and after a detailed review of published literature, the author concludes there is no confirmatory scientific evidence to support these hypotheses.
\end{abstract}

Received date: January 18, 2016

Accepted date: February 4, 2016

Published date: February 10, 2016

Citation: Wimalawansa, S.J. Effect of Water Hardness on Non-Communicable Diseases, Including Chronic Kidney Disease of Multifactorial Origin (CKDmfo/ CKDuo). (2016) J Environ Health Sci 2(1): $1-11$.

Keywords: Calcium; Cardiovascular disease; Diabetes; Hard water; Magnesium; Reproductive health; Reverse osmosis; Soft water; Renal stone

DOI: $10.15436 / 2378-6841.16 .029$

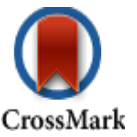

\section{Introduction}

Water is essential not only for proper bodily functions and hydration but also for survival of living beings. Drinking water needs to be clean and safe (potable) and is essential for protecting health and the survival of humans ${ }^{[1]}$. Consumption of water that is contaminated, whether with microbes, biotoxins or chemicals, will lead to ill health and, may cause premature death ${ }^{[2]}$. Several epidemiologic studies have attributed relationships between drinking hard water or soft water with increasing risks for cardiovasculardiseases $^{[3,4]}$, certain cancers ${ }^{[5]}$ and congenital and reproductive abnormalities ${ }^{[6,7]}$, but recent studies failed to support any of these hypotheses.

It has been estimated that approximately $20 \%$ of the world's population uses water from unprotected sources, $32 \%$ from protected sources, and the balance (48\%) from centralized and purified pipe-borne water supplies. Approximately 900 million people lack access to safe water supplies (i.e., about one in eight people ${ }^{[8]}$. Approximately $70 \%$ of people drink water from homes, 
whereas the rest obtain water elsewhere, such as in workplaces or at schools. In addition, people get a considerable amount of water from other sources, such as food and beverages. While drinking water and beverages comprise $80 \%$ of water intake, food is the main source of macro- and micro-nutrients and vitamins (approximately 95\%) for living beings.

Because of the global scarcity of freshwater, increased use of water from sources such as recycled water, rainwater, desalinated water, and water obtained from deep tube wells has taken place during the past five decades in many developing countries. Tube wells however, can tap into the ground water table that contains high temporary hardness $\left(\mathrm{CaCO}_{3}\right.$ equivalents). The latter is mostly due to dissolved calcium and magnesium), although some have excessive amounts of other naturally occurring components including fluoride ${ }^{[9]}$.

The effects of hard (and soft) water on human diseases are a matter of controversy ${ }^{[10-16]}$. Some studies report that the higher thehardness of water, the lower the incidence of cardiovascular diseases (CVD $)^{[1-13,17,18]}$, but many other studies do not corroborate this finding ${ }^{[15,19,20]}$. The reported associations can be explained by confounding variables, including distance from the equator (thus the changes of serum 25 -hydroxyvitamin $\mathrm{D}[25(\mathrm{OH}) \mathrm{D}]$ and $1,25(\mathrm{OH})_{2} \mathrm{D}$ levels $)^{[21,22]}$, ethnicity, climate changes, socio-economic status, personal and dietary habits, and other risk factors ${ }^{[3,4]}$.

\section{Causes of water hardness}

Hard water usually is defined as water that contains mostly high levels of calcium and magnesium ions. Nevertheless, hardness also can be caused by other ions and dissolved compounds, including multivalent cations such as aluminum, barium, strontium, iron, zinc, and manganese. Divalent cations have a tendency to couple with anions in the water to form stable salts. The type of anion found in hard water distinguishes between the two types of hardness: carbonate and non-carbonate forms. Under normal circumstances, mono valent ions such as sodium and potassium do not contribute to hardness, but these ions cause salinity and increasing electrical conductivity and ionic strength, making such water somewhat unhealthy and unpalatable.

Metals combined with anions form alkalinity, which causes carbonate hardness. Alkalinity has the capacity to neutralize acids and is attributed to compounds such as carbonate, bicarbonate, hydroxide, as well as borate, silicate, and phosphate. Carbonated hard water (also called temporary hardness because the hardness can be removed by boiling the water) contains calcium carbonate $\left[\mathrm{CaCO}_{3}\right]$, magnesium carbonate $\left[\mathrm{MgCO}_{3}\right]$, calcium hydroxide $\left[\mathrm{Ca}(\mathrm{OH})_{2}\right]$, magnesium hydroxide $\left[\mathrm{Mg}(\mathrm{OH})_{2}[\mathrm{Ca}(\mathrm{HCO})]\right.$, calcium (bicarbonate $\left.)_{2}\right]$ and magnesium bicarbonate $\left[\mathrm{Mg}\left(\mathrm{HCO}_{3}\right)_{2}\right]$. Most, but not all carbonate hardness, can be removed by boiling water, by which carbonated calcium and magnesium salts will be precipitated. Therefore, if hard water protects from diseases, the boiling of water (including making tea or coffee) would remove this hypothetical beneficial effect.

Total water hardness includes both carbonate and non-carbonate forms of hardness, which are mostly, associated with calcium and magnesium salts. Based on the amount of dissolved salts, water is categorized as soft ( 0 to $60 \mathrm{mg} / \mathrm{L}$ ), moderate (61 to $120 \mathrm{mg} / \mathrm{L}$ ), hard (121-180 mg/L) and very hard (more than $180 \mathrm{mg} / \mathrm{L}$ ). Non-carbonated water hardness forms when metals combine with anything other than alkalinity. Compounds causing non-carbonated hardness include calcium sulphate $\left[\mathrm{CaSO}_{4}\right]$, magnesium sulphate $\left[\mathrm{MgSO}_{4}\right]$, calcium chloride $\left[\mathrm{CaCl}_{2}\right]$, and magnesium chloride $\left[\mathrm{MgCl}_{2}\right]$. This non-carbonate hardness in water cannot be removed by boiling the water. Because the removal methods are different, it is useful to differentiate between the two types of hardness.

Groundwater hardness generally derives from water percolating through soil and weathering rocks, that contain carbonateminerals, but also can be caused by anthropogenic activities. The most common sources of water becoming hard are calcium-containing limestone and magnesium-containing dolomite. Therefore, groundwater (e.g., obtained via deep tube wells) usually has a greater hardness than does surface water ${ }^{[23]}$. Once water is ingested, several factors, such as concentration, ionic constituents, and acidity, influence many physiological phenomena; gastrointestinal absorption, renal tubular excretion and re-absorption of calcium and Ions, heavy metals, and other constituents. Depending the needs of the body, hormonal and ionic-interactions, especially calcium, magnesium, and potasium, and key micro-nutrients would affect the human health beneficially or adversely.

\section{Postulated health effects attributable to water hardness}

During the past five decades (and until early 2000), numerous reports emphasized that consumption of hard water had health benefits, while soft water may cause disease. Nevertheless, no confirmatory research data available to support either of these claims. Several World Health Organization (WHO) and other reports ${ }^{[1,24]}$ indicate that consuming hard water or soft water has no known adverse health effects on humans ${ }^{[13,15]}$, except for formation of renal stones in the presence of chronic dehydration or genetic susceptibility. The claimed health effects of hard water are mainly attributable to the effects of calcium and magnesium salts ${ }^{[10-13,25]}$. Although hard water may supplement some minerals to the total calcium and magnesium intake, its dietary contribution to absorbable minerals is negligible.

The intestinal absorption of calcium is tightly controlled by interlinked homeostatic mechanisms, predominately by two key calcium regulating hormones: 1,25 (dihydroxy) vitamin $\mathrm{D}$ and parathyroid hormone ${ }^{[26]}$. Calcium in the intestine is known to interfere with the absorption of iron, zinc, magnesium, and phosphate, certain medications, and many other constituents, reducing the bioavailability not only of calcium but also other ions and compounds. Built-in evolutionary physiological mechanisms regulate the rate of absorption of these minerals that is designed to keep a healthy homeostasis within the body.

Absorption of minerals from the intestine is not linear: the higher the oral intake, lower the fractional gastrointestinal absorption. Similarly, to keep the physiological homeostasis in the body, there are tightly regulated and hormonally controlled mechanisms present in the kidney, where a delicate balance of the reabsorption and excretion of ions occurs. Thus, the presence of renal insufficiency invariably leads to difficulty in excreting certain ions, such as potassium and magnesium, so hyperkalemia, 
hypermagnesemia, and hypercalcemia occur in those with renal failure. Also tend to accumulate toxins, heavy metals, arsenic, etc.

\section{Postulated associations of water hardness and diseases}

Worldwide, the incidence of CVD varies widely in different geographical regions. Although the role of water hardness has been evaluated for many years, none of the hypotheses put forward to explain this association have been substantiated, and no particular element in hard water has been found conclusively to be associated with or causative of CVD.

Few studies have reported that CVD death rates are inversely correlated with the concentration of magnesium in drinking water $^{[27]}$, and that magnesium decreases deaths from strokes ${ }^{[28]}$. However, others have failed to confirm this hypothesis ${ }^{[2,30]}$. Reported high "dietary" intakes of calcium ${ }^{[2,31,32]}$ or magnesium (not in drinking hard water) have been associated with beneficial health effects, such as a lowering of blood pressure ${ }^{[32]}$.

Several past epidemiologic studies have indicated negative associations of certain types of cancer, including gastric ${ }^{[33]}$, co$\operatorname{lon}^{[5]}$, esophageal, and ovarian cancers ${ }^{[34]}$, with the hardness of water, but such results have not been corroborated in recent studies. The reported gastrointestinal health benefits associated with hard water may come from the potential laxative effect of magnesium, negating constipation and thus minimizing intestinal cell exposure to potential carcinogens. However, a correlation between lifelong dietary intake of calcium and magnesium and beneficial effects on the skeleton ${ }^{[35-37]}$ has been reported, but data pertinent to drinking water and bone health are sparse ${ }^{[38]}$ and hypothetical.

Others have claimed that hard water containing magnesium may have beneficial effects on diabetes because kinases and other ATP-related enzymes and channels regulating insulin action are magnesium dependent. Whether the low intracellular magnesium content is secondary to or precedes the insulin resistance however, is unclear. Nonetheless, recent evidence suggests that subclinical chronic magnesium deficiency may precipitate a diabetic state. The absorbable magnesium in hard water is negligible; diet, but not drinking water, provides more than $98 \%$ of the daily magnesium requirement.

\section{Currently acceptable WHO limits in water hardness}

Hardness in most circumstances is caused by calcium and magnesium salts (mostly carbonate); acceptable limits are as great as $500 \mathrm{mg} / \mathrm{L}$ (and in certain circumstances as great as $1,000 \mathrm{mg} / \mathrm{L}$ ). pH between 6.5 and 8.0; U Recommended upper limits are, calcium $75 \mathrm{mg} / \mathrm{L}$, and magnesium $50 \mathrm{mg} / \mathrm{L}$; alkalinity $250 \mathrm{mg} / \mathrm{L}$ : $\mathrm{NO}_{3}^{-} 45 \mathrm{mg} / \mathrm{L}$; $\mathrm{Cl}^{-} 250 \mathrm{mg} / \mathrm{L}$; SO $200 \mathrm{mg} / \mathrm{L}$ : TDS $500 \mathrm{mg} / \mathrm{L}$; and EC $1,800 \mu \mathrm{S} / \mathrm{cm}$. In the CKDmfo affected NCP regions, well water TDS levels vary from 250 to $900 \mathrm{mg} / \mathrm{L}$. Whereas in Jaffna, Ampara, and Puttalam districts, etc., where the hardness is greater than 1,500 mg/L, yet the incidence of CKDmfo is minimal, even though they use similar quantities of same agrochemicals.

\section{Water hardness contributes to formation of renal stones}

The consumption of hard water has no major advantages or disadvantages, but it can cause renal/kidney stones, especially in the presence of chronic dehydration. These calcium-containing renal stones are particularly common in those who are working outdoors, such as farmers and construction workers in sunny, drier regions in tropical countries. If harsh climate and chronic dehydration cause CKDmfo, then those manual workers in the middle eastern countries sould have develop this, but this is not the case. Large renal stones (e.g., staghorn calculi) or stones that obstruct the urinary pathways can lead to structural and functional renal impairment, and infrequently, renal failure.

The hardness of water is predominantly attributable to the presence of carbonate and sulphate salts of calcium and magnesium. More than $75 \%$ of kidney stones (nephrolithiasis) contain calcium salts as carbonate, oxalate, and phosphate. The remaining $25 \%$ of kidney stones are composed of uric acid, struvite, cysteine, and other components, mostly in those with genetic predisposition. Nevertheless, in additional to genetics, the formation of renal stones is influenced by others, including metabolic, nutritional, personal habit, and environmental factors.

There are also several metabolic factors involved in stone formation, including hypercalciuria, hypocitraturia, hyperuricosuria, hyperoxalaturia, cystinuria, and chronic infections. Environmental and nutritional factors that facilitate formation of renal stones include chronic dehydration, high salt intake, a diet rich in animal proteins, a calcium-rich diet, and consumption of hard water over a long period. While some studies have shown no association between water hardness and the incidence of renal stone formation, others have suggested the consumption of soft water as a mode for preventing nephrolithiasis caused by calcium ${ }^{[39]}$.

The prevalence of kidney stones in the North Central Province (NCP) in Sri Lanka (a part of the dry zone in the country) is more than three times higher in certain villages (personal data and hospital statistics) than in cities. In the long run, some of these stones could lead to obstructive nephropathy, renal damage, and eventually chronic renal failure/disease (CRF/CKD). The high incidence of renal stones in the NCP (including calcium-based staghorn calculi) is attributable to the combination of drinking hard water, chronic dehydration, and not drinking adequate amounts of water, because of unpleasant taste in water.

\section{Chronic kidney disease of multifactorial origin (CKDmfo)}

Chronic kidney disease of multifactorial origin (CKDmfo), also known as CKD of uncertain/unknown origin/etiology (CKDuo), affects several equatorial (tropical) countries in Asia ${ }^{[40-42]}$, Southern Europe, and Central America ${ }^{[9,43]}$. Etiologically, the disease is unrelated to CKD resulting from nephrolithiasis, and common causes of CKD, hypertension, and diabetes. Virtually all ofCKDuo-affected countries are economically poor and have agriculture-based economies and have rampant malnutrition and poverty.

Within each affected tropical country, regions in which CKDmfo/CKDuo is prevalent are located in the dry zones, in flat- 
lands with little drainage, and have residents who are economically disadvantaged and have little access to modern health care ${ }^{[4]}$. Although there are larger hospitals within the cities, more than $80 \%$ of people live in rural, remote villages in these regions and have no access to such healthcare facilities. Compared to cities and urban areas, CKDmfo-affected regions and villages in all of these countries have been relatively neglected by their governments. Many of those with the disease are between the third and fifth decades of (productive) life, mostly males; the death rate among affected individuals exceeds 5\% per year.

Diagnostic difficulties: It is traditional to use serum creatinine to calculate, estimated glomerular filtration rate (eGFR), with an equation using serum creatinine ${ }^{[45-47]}$, such as the Cockroft-Gault equation ${ }^{[47,48]}$ or the MDRD Study equation ${ }^{[49]}$. Instead of creatinine, cystatin $\mathrm{C}$, a low molecular weight $(13-\mathrm{kDa})$ cysteine protease inhibitors that is produced by all nucleated cells can be considered as a better alternative to serum creatinine for estimating GFR, es.pecially for those with non glomerular renal failure ${ }^{[50]}$.

Due to the ineffective methods use, such as urinary albumin or micro-albumin:creatinine ratios (ACR or MCR) for screening and diagnosis, the majority of CKDmfo affected people, at the time of (late) diagnosis have marked renal tubular damage (with relative glomerular sparing) and elevated serum creatinine requiring renal dialysis. The use of MCR is not a true screening test for CKDs. It is intended to identify development of early signs of nephropathy in those with diabetes and hypertension [51].

Because the CKDmfo is primarily a renal tubular disease, the glomerular-specific tests, such as the microalbumin-to-creatinine ratio, are insensitive in identifying those who are having CKDmfo during the early stages of renal impairment ${ }^{[44,52]}$. The late diagnosis is attributed in part, for people not seeking care early in the disease (because they do not have specific signs or symptoms of renal failure) and the use of insensitive (and inappropriate) tools for screening and diagnosis of tubule-interstitial renal diseases.

Hypothesis: Causal hypotheses put forward include agrochemicals, heavy metals, ionicity of water (sodium and phosphate in particular), consumption of illegally brewed alcohols and smoking of locally grown tobacco, leptospirosis, chronic volume depletion/ dehydration, oxidative stress at the cellular level, and occupational exposure to harsh environments and environmental toxins ${ }^{[9,44,53]}$.

Figure 1 summarizes all broader hypotheses put forward to-date to explain the etiology of CKDmfo in Sri Lanka. However, none has been proven to be causative yet.

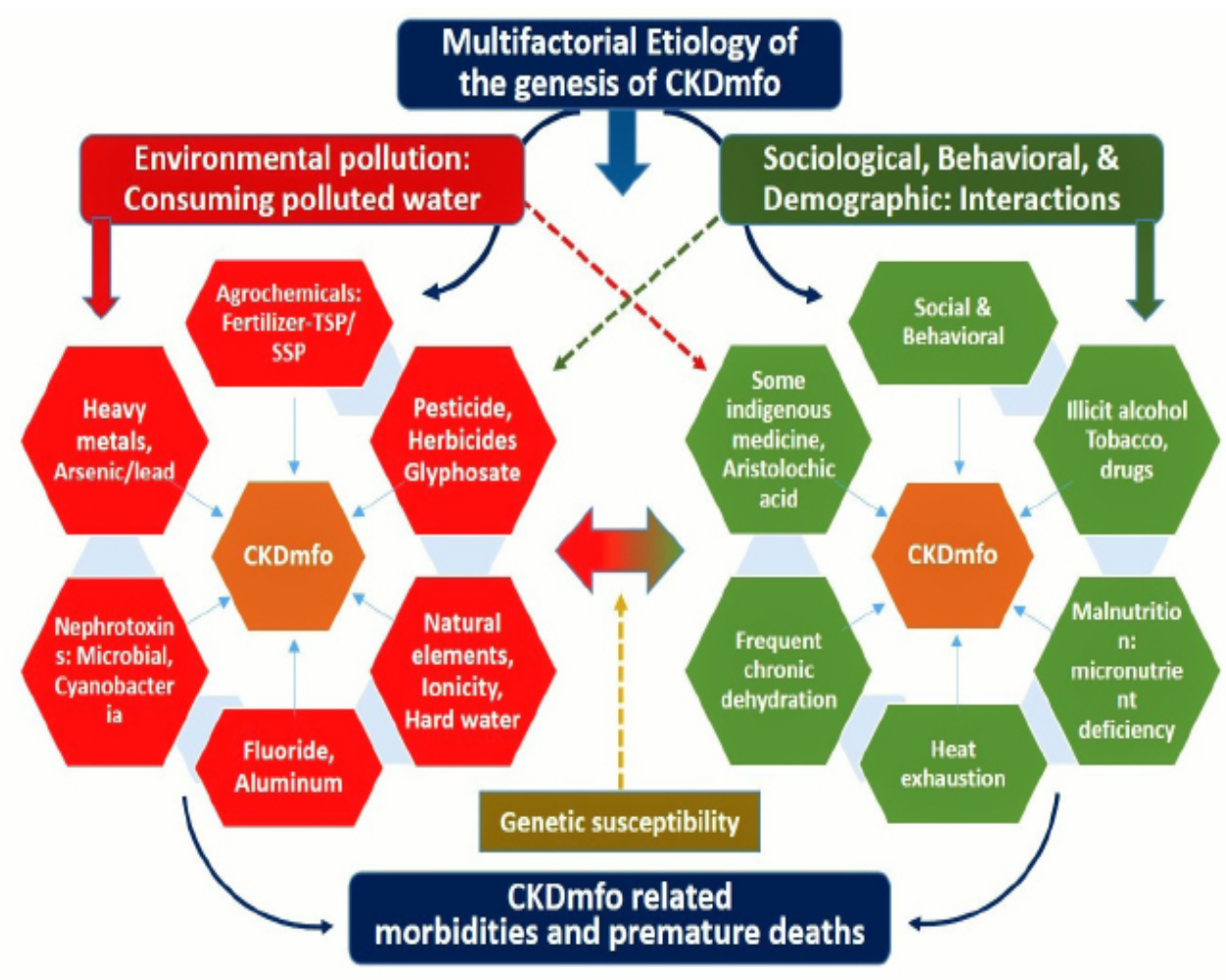

Figure 1: Etiological factors are broadly divided into environmental, sociological, and behavioral. Many of the factors illustrated within each group are likely to interact with each other and may have additive or synergistic, nephrotoxic effects in the origin of chronic kidney disease of multifactorial origin (CKDmfo).

Detailed water analyses by several groups concluded that except for fluoride and phosphate, the concentrations of heavy metals and agrochemicals in drinking water, soil and food sources in the NCP are far below the maximum allowable levels (MAL) $(\mathrm{MAL})^{[41,54,55]}$. Mean-

while, some have suggested the increased ionicity (i.e., salinity, not hard water) as a potential cause for CKDmfo in Sri Lanka ${ }^{[56,67]}$. There are a number of myths associated with the genesis of CKDmfo. Some hypotheses were proposed without any scientificfic basis, other have never tested. This article explores the claims whether there is any relationship between the consumption of hard water and CKDmfo, as has been postulated by some ${ }^{[58]}$.

One group recently drew attention to the theoretical interactions of hard water with one of the phosphonate ingredients in the herwww.ommegaonline.org 
bicide glyphosate ${ }^{[58,59]}$. The group proposed glyphosate as the cause for the disease, in association with heavy metals. Glyphosate was introduced to the CKDmfo-affected NCP region in 2001 (following the expiry of the Monsanto patent). The widespread use of glyphosate commenced in the CKDmfo-affected regions only after the cheaper, but for humans, more than thousand-fold toxic herbicide, paraquat was banned in $2007^{[9,60]}$. Nevertheless, this is many years after the identification of CKDmfo in the region, which makes the glyphosate hypothesis highly unlikely and irrelevant to the genesis of CKDmfo ${ }^{[4]}$.

In addition, the postulated mechanism for the formation of the glyphosate-arsenic/cadmium complexes (which are effectively insoluble) is thermodynamically not feasible. Both being anions, glyphosate does not form complexes with arsenic. Moreover, while glyphosate was widely used in all agricultural areas in the country, only in certain geographic localities people are prone to develop CKDmfo. This is also apply to all postulated nephrotoxins. These facts not only invalidate the glyphosate hypothesis ${ }^{[59]}$, but also confirms that it is highly unlikely that glyphosate cause or even associated with CKDmfo.

\section{Electrical conductance and ionicity}

If the ionicity (i.e., increase $\mathrm{NaCl}$ in drinking water) causes $\mathrm{CKDmfo}$, then thousands of people who live in Kalutara Galle, Puttalam, Trincomalee, Jaffna and souther part of Hambantota districts would have developed this disease; but this is not the case. In international system of units (SI unit), conductivity is expressed in Siemens per meter $(\mathrm{S} / \mathrm{m})[1 \mathrm{EC}=1 \mu \mathrm{S} / \mathrm{cm}]$. However, for most scientific work it is expressed as $\mu \mathrm{S} / \mathrm{cm}$ (http://www.mbhes.com/conductivity_measurement.htm ).

For example, deionized (or pure) water has a conductivity of about $0.055 \mu \mathrm{S} / \mathrm{cm}$, typical drinking water is in the range of $50-1000 \mu \mathrm{S} / \mathrm{cm}$; reverse osmosis purified water $50-100 \mu \mathrm{S} / \mathrm{cm}(25-50 \mathrm{ppm})$ [in potable water up to, $1,055 \mu \mathrm{S} / \mathrm{cm}(525 \mathrm{ppm})$ ]; and sea water, approximately, $56,000 \mu \mathrm{S} / \mathrm{cm}(28,000 \mathrm{ppm})$ (i.e., sea water's conductivity is one million times higher than that of deionized water; $10^{6} \mu \mathrm{S} / \mathrm{cm}=10^{3} \mathrm{mS} / \mathrm{cm}=1 \mathrm{~S} / \mathrm{cm} .1 \mu \mathrm{S} / \mathrm{cm}$ is then equivalent to about $0.64 \mathrm{mg}$ of NaCl per kg of water) [http://www.lenntech. com/applications/ultrapure/conductivity/water-conductivity.htm].

When water is used for irrigation, part of it evaporates and is consumed by plants, concentrating the amount of dissolved -solids. The remaining higher-specific-conductance water re-enters the streams with the irrigation return flow. Thus, the dissolved solids' concentration and the specific electrical conductance in the remaining water are proportionally increased ${ }^{[61]}$. A similar event happens to a greater extent in well-water during the dryer season, when the water hardness, electrical conductivity (EC), ionic concentrations, and total dissolved solids (TDS), all increases. Such water not only has a bad taste but in the longer term may harm humans and animals due to consumption of concentrated chemicals and toxin contents.

The term "ionicity" is a misnomer and cannot be defined clearly. Its definition is vague: "the ionic character of a bond", "molecules to a degree something is ionic," etc. Consequently, it is not used by the WHO or the EPA, and very rarely used by those in the scientific community when discussing water-related matters. Moreover, since there are no physiologic or pathologic correlation, or association with ionicity to the genesis of CKDmfo, the use of this term and the concept is irrelevant.

However, electrical conductance (EC) (i.e., ability to conduct an electric current) is a better understood measure of pollution of water with salt. It is directly related to the total dissolved salt content of the water. It is defined as the ratio between the current density $(\mathrm{J})$ and the electric field intensity (e) and, is the opposite of the resistivity $\left(\mathrm{r},\left[\mathrm{W}^{*} \mathrm{~m}\right]\right): \mathrm{s}=\mathrm{J} / \mathrm{e}=1 / \mathrm{r}$. Using the EC, one can also estimate the total dissolved salt concentration in water by multiplying its temperature-normalized electrical conductivity by a factor of between 0.5 and 1.0 for natural waters. The value of this factor depends on the type of dissolved solids. A widely accepted value to use for calculating TDS is 0.67 , using the equation; TDS (in $\mathrm{mg} / \mathrm{L}$ or ppm) $=0.67 \times \mathrm{EC} 25 \mathrm{in} \mu \mathrm{S} / \mathrm{cm}$ (or micromhos/cm).

\section{The lack of relevance of Hofmeister series to CKDmfo}

The Hofmeister series (also called lyotropicseries) explains a series of salts that have consistent effects on the solubility of proteins achieved via altering the secondary and tertiary structure of protein ${ }^{[62]}$, where anions have a more potent effect than do cations $^{[63]}$, at the following order of potency:

$\mathrm{F} \approx \mathrm{SO}_{4}^{2-}>\mathrm{HPO}_{4}^{2-}>$ Acetate $>\mathrm{Cl}^{-}>\mathrm{NO}_{3}^{-}>\mathrm{ClO}_{3}^{-}>\mathrm{I}^{-}$

The order of potency of cations is:

$\mathrm{NH}_{4}^{+}>\mathrm{K}^{+}>\mathrm{Na}^{+}>\mathrm{Li}^{+}>\mathrm{Mg}_{2}^{+}>\mathrm{Ca}_{2}^{+}$

Although the mechanism of the Hofmeister series is not fully understood, it is thought that it is not due to alteration of the structure of water molecules ${ }^{[63]}$. It has been suggested that protein solubility and the structural alteration in the presence of the above mentioned ions are due to specific interactions among "ions-proteins-water" molecules. However, the ionic concentrations necessary for denaturing protein are several orders of magnitude higher than what is present in drinking water in the CKD-affected regions.

While important for laboratory experiments, and solubility and precipitation of proteins (purification), Hofmeister series of ionic potencies has no biochemical or clinical relevance to CKDmfo or its geographical context. Most of the cations ( $\mathrm{Na}$, $\mathrm{Mg}$ ) and anions $(\mathrm{Cl})$ present in well water are either week in the Hofmeister series or the concentrations of more potent ions are too low to have an effect on membrane or structural changes of proteins, especially in vivo. Thus, the theoretical potential of Hofmeister series is irrelevant to human physiology and CKDmfo.

The only exception to this is the fluoride anion:-the top of the Hofmeister anion series, but it is not present in much of the 
shallow well water used by those with CKDmfo; fluoride concentration in water is too little to cause alternation of protein structures. Nevertheless, at physiologic aqueous conditions, fluoride ions above $1.5 \mathrm{mg} / \mathrm{L}$ could impact enzymatic reactions and biotransformations ${ }^{[63-67]}$, but such levels are unlikely to achieve in vivo. Therefore, one would not expect any of the ions in the Hofmeister series to have an in vivo deleterious impact, clinical relevance, or correlation with the genesis of CKDmfo.

\section{Increasing salinity in groundwater and CKDmfo}

In the regions affected by CKDmfo, the water table fluctuates markedly throughout the year. This is in part because of prolonged dry seasons followed by torrential rain $^{[9,44]}$. This scenario has been markedly worsened during the past three decades following the introduction of thousands of tube wells, particularly large capacity agro-wells over-exploiting the groundwater reserves. Most of the NCP region consists of low humic gley soil and shallow non-permeable hard bedrock underneath. The presence of predominantly clay soil with less sand and the over-extraction of groundwater through agro-wells have altered the underground water dynamics in the region, drawing not only salinity but also fluoride into the ground-water. The situation may have been aggravated by the diverted water from the Mahaweli River that has enriched the reservoirs water in NCP since the mid-1970s. The resulting increased surface water table together with the drawing underground water to surface through agro-wells, may play a role in gradually dissolving the subsurface salt layers increasing water salt content.

Although the regolith aquifer from the NCP region extends towards Ampara and Monaragala and partially toward the Puttalam districts, the soil structures in these areas however, are markedly different. Moreover, although these areas have hard water, use same agrochemicals, and have higher amounts of fluoride in water, they have a lower incidence of CKDmfo ${ }^{[4]}$. Thus, excessive withdrawal of groundwater in the presence of particular soil types and regolith aquifer/rock layers tend to increase the salt and fluoride contents of ground-water over time, that eventually also seeps into shallow wells.

Nevertheless, similar water issues have been prevailing along the coastline and in Jaffna Peninsula for more than hundred years, but only since 2015 have few patients with CKDmfo been identified in these areas. Although this seems an attractive hypothesis, the levels of $\mathrm{NaCl}$ (salt) and fluoride present in well water in the NCP by themselves are too little to cause CKDmfo.

Although $\mathrm{NaCl}$ content (EC) is an unlikely factor, the increasing content of fluoride in the water table at least indirectly, could contribute to this disease ${ }^{[44,60]}$. In addition, if $\mathrm{NaCl}$ or fluoride is the cause of CKDmfo, it is unclear why only $5 \%$ of the people in the NCP region are affected, why men are affected more than women, or why the disease is now spreading to regions far away from the NCP where there are no issues with water salinity or even fluoride.

\section{Drinking water containing phosphate does not cause CKDmfo}

Unlike nitrates $^{[68]}$, there is no known human health hazard associated with phosphates in water within the range observed in mst water bodies ${ }^{[61,69,70]}$. Moreover, at these levels in water, there is no evidence that phosphates cause kidney damage of any sort. However, if phosphate exceeds $1 \mathrm{mg} / \mathrm{L}$ in drinking water, it may cause other adverse reactions, including unpleasant taste.

The two main sources of land application of phosphates are the excessive use of phosphate fertilizer and manure from intensive livestock farming. These lead to excess phosphate in water, resulting in phosphate eutrophication of water ${ }^{[61,71,72]}$. While the former is applicable to many agricultural regions, including in Sri Lanka, the latter is the predominant issue in many European communities today ${ }^{[61,73]}$. There are different types of phosphates in water, but the total phosphate-phosphorous-level is what need $\mathrm{s}$ to be calculated when testing the water quality, reference to its effects on aquatic life. The natural background levels of total phosphorus generally are less than $0.03 \mathrm{mg} / \mathrm{L}$, whereas the natural orthophosphate levels usually range from 0.005 to $0.05 \mathrm{mg} / \mathrm{L}^{[61]}$.

The average phosphate levels in most reservoir water in the NCP in Sri Lanka are above $\geq 0.1 \mathrm{mg} / \mathrm{L}^{[57,61]}$ and thought to be harmful to marine life ${ }^{[74]}$. When the phosphate levels in water are very high, the water has a bad taste and can cause digestive problems. However, no known human ailment or disease, including CKD, has been found to be caused by consuming water with phosphate levels averaging $0.1 \mathrm{mg} / \mathrm{L}$ in water ${ }^{[75]}$.

Based on the higher phosphate levels in water and the Hofmeister series on anions, it has been postulated that phosphate and/or 'ionicity' may be causally related to CKDmfo ${ }^{[76]}$. Nevertheless, most people in the CKDmfo-affected areas drink well water (surface water) that contains lesser amounts of phosphate (less than $0.05 \mathrm{mg} / \mathrm{L}$ ) and fluoride, and EC is between 400 and $700 \mu \mathrm{s}$. These values are well within the maximum "desirable electrical conductivity" for drinking water (750 $\mu$ s), as per the Sri Lanka Standard614:1983 and SLS 894.

Both the ionicity and the phosphate levels in drinking water sources (e.g., shallow wells, from which more than $80 \%$ of people in the CKDmfo-affected region obtain their drinking water), are within the allowable limits. There are reports indicating that water salinity has increased in the $\mathrm{NCP}^{[76,77]}$. While, it causes bad taste, similar with water hardness higher salinity alone does not cause CKDmfo ${ }^{[44,61,78]}$. Moreover, only less than $20 \%$ of the affected people are drinking water from sources other than shallow dug wells. Aforementioned facts exclude both salt content (ionicity) and the phosphate as a causative factor for CKDmfo ${ }^{[79]}$.

\section{Drinking soft water does not cause human diseases}

Some argue that the "softness" of drinking water is implicated in some human pathologies. Most of the divalent cations, such as calcium and magnesium, as well as a multitude of anions that humans consume come through the diet, not via drinking water. Human bodies have elaborate hormonal systems to control absorption and excretion of cations and anions (ions) to maintain a healthy physiological balance. Thus, small increases or decreases or even the absence of these ions in drinking water have insignificant effects on human health. 
With variations in daily dietary calcium intake (from 300 to $1,000 \mathrm{mg}$ ), balance is achieved easily in the presence of the intact "parathyroid-vitamin D hormonal axis," which strictly maintains the physiological calcium and phosphate levels in blood. Therefore, the suggestion that minor changes in ionic content of drinking water would affect humans health, is highly unlikely. Neither an increase (as in hard water) nor decrease (in most bottled water or water purified via the RO method in the absence of dremineralization) calcium and magnesium levels in drinking water are likely to affect human health adversely.

Similarly, ingestion of small quantities of phosphate in water (approximately $0.1 \mathrm{mg} / \mathrm{L}$, such is present in the reservoir waters in the NCP and other parts of Sri Lanka and elsewhere ${ }^{[80]}$ would not lead to renal failure. In fact, the blood phosphate concentration in humans is several orders of magnitude greater [i.e., ranging, 35 to $45 \mathrm{mg} / \mathrm{L}(1.12$ to $1.45 \mathrm{mmol} / \mathrm{L})$ ] than in water. Moreover, for comparison, one cup of milk has $230 \mathrm{mg}$ of phosphorus (approximately, $1.0 \mathrm{~g}$ of phosphorus per L of milk) [USDA Nutrient Database forStandard Reference. http://www.nal.usda.gov/fnic/foodcomp/search]. The RDA allowance for phosphorus is $700-1250 \mathrm{mg} /$ day. One needs to compare this to $<0.1 \mathrm{mg} / \mathrm{L}$ in reservoir water.

More than $85 \%$ people in the CKDmfo-affected areas consume water directly from wells, where the phosphate contents are negligible ${ }^{[5,76,78,81]}$. Therefore, the suggestion that phosphate in water (and thus, ionicity) is causing CKDmfo ${ }^{[57]}$ is unlikely $^{[9,44]}$. Nevertheless, in many villages (especially tube-well water), fluoride levels exceed the recommended MAL levels in water ${ }^{[2,44]}$.

The fluoride content of groundwater obtained from many deep tube wells in the region exceeds $0.8 \mathrm{mg} / \mathrm{L}$, whereas the new upper limit recommended by WHO for tropical countries is $0.6 \mathrm{mg} / \mathrm{L}$ (WHO 1994). However, the levels of fluoride in groundwater are not consistent; they vary between 0.52 and $4.90 \mathrm{mg} / \mathrm{L}$ (mean value, $1.4 \mathrm{mg} / \mathrm{L}$ ), which is much higher than the $\mathrm{MAL}^{[82,83]}$. When hard water containing fluoride is boiled, it forms an insoluble fluoride complexes and precipitate. Thus, although fluoride is considered at the top of the Hofmeister series and the levels are higher in some drinking water sources, the amount entering into human bodily systems is much less than what is measured in water; thus less harmful than one would otherwise estimate.

More than $95 \%$ of daily mineral and micronutrient requirements in humans are obtained through the diet. For example, each average sized banana (or any large fruit) has more beneficial and absorbable minerals content, micronutrients, and vitamins than an entire day's supply (e.g., 2.0 liter) of normal tap or bottled water. So, the concept that water is a key source of minerals is false.

Table 1: shows the average mineral content and other constituents in an average size banana $(\sim 200 \mathrm{~g})$ in comparison with the typical daily intake of $2.0 \mathrm{~L}$ water.

\begin{tabular}{|c|c|c|c|}
\hline \multicolumn{4}{|c|}{ A comparison of mineral and micronutrient constituents of a banana compared with constituents of $2.0 \mathrm{~L}$ of normal drinking water } \\
\hline \multicolumn{2}{|c|}{ Constituents of banana } & \multicolumn{2}{|c|}{ Constituents in water } \\
\hline Medium size banana, $200 \mathrm{~g}$ & Content & Water, $2.0 \mathrm{~L}$ & Content \\
\hline $\mathrm{Ca}$ & $20 \mathrm{mg}$ & $\mathrm{Ca}$ & $100 \mathrm{mg}$ \\
\hline $\mathrm{Mg}$ & $65 \mathrm{mg}$ & $\mathrm{Mg}$ & $25 \mathrm{mg}$ \\
\hline $\mathrm{K}$ & $700 \mathrm{mg}$ & $\mathrm{K}$ & $10 \mathrm{mg}$ \\
\hline $\mathrm{Cl}$ & $6 \mathrm{mg}$ & $\mathrm{Cl}$ & $86 \mathrm{mg}$ \\
\hline $\mathrm{SO}_{4}$ & $60 \mathrm{mg}$ & $\mathrm{SO}_{4}$ & $90 \mathrm{mg}$ \\
\hline $\mathrm{PO}_{4}$ & $80 \mathrm{mg}$ & $\mathrm{PO}_{4}$ & $90 \mathrm{mg}$ \\
\hline $\mathrm{Se}$ & $1.5 \mu \mathrm{g}$ & $\mathrm{Se}$ & $<0.01 \mu \mathrm{g}$ \\
\hline $\mathrm{F}$ & $0.02 \mathrm{mg}$ & $\mathrm{F}$ & $\sim 0.8 \mathrm{mg}$ \\
\hline Micronutrients & $20+$ & Micronutrients & None \\
\hline
\end{tabular}

The daily consumption of one banana will provide more mineral content and essential micronutrients than that provided by the total daily intake of water. In fact, on a per-weight basis, many other fruits and vegetables contain $\mathrm{more} \mathrm{Ca}_{2}^{+}$and $\mathrm{Mg}_{2}^{+}$than does a banana. Thus, it is a false expectation to believe one would receive a major portion of the daily requirement of minerals through drinking water.

No meaningful difference to the daily mineral intake and absorption in the gastrointestinal tract would be found with the consumption of tap water, mineralized or unmineralized bottled water, or water purified from reverse osmosis (RO). Mineralized bottled water is a rich man's entity that is not necessary from a physiological point of view. Because of the tight hormonal regulations and build-in homeostatic mechanisms, when there is an excess mineral in the intestine, it absorbs less, and when there is less, the fractional absorption of minerals increases; thereby controlling and maintaing the mineral homeostasis in the body.

Figure 2 illustrates the plausible multiple interactions and final common pathway of causing renal tubular damage in persons with CKDmfo. 


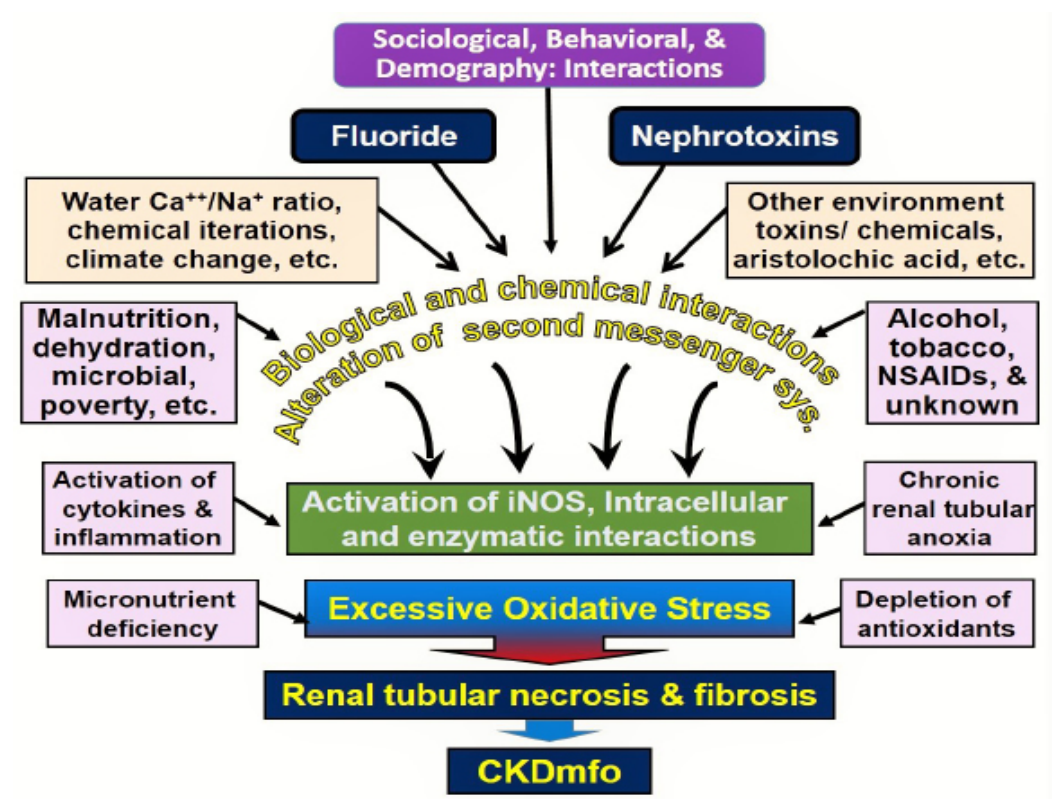

Figure 2: Conceivable multiple interactions, multifactorial etiology, and the final common pathway of triggering renal tubular fibrosis are illustrated in people with CKDmfo (NSAIDs = non-steroidal anti-inflammatory drugs; iNOS = inducible nitric oxide synthase; CKDmfo = chronic kidney disease of multifactorial origin).

\section{Hard water contributes to nephrolithiasis (renal stones) but do not cause CKDmfo}

Chronic dehydration secondary to harsh climatic conditions, droughts, and high temperature in the work environment; increased sweating; and drinking less water (in part due to hardness and thus un-palatability of water) lead to a higher prevalence of renal stone disease in those who are living and working in dry zonal regions in tropical countries (so as in outdoor workers in middle-eastern countries and elsewhere), including the NCP in Sri Lanka.

Nevertheless, these harsh conditions and agricultural practices have existed for centuries in the region and have not significantly changed. However, the increase of average temperature and prolongation of drought seasons associated with climate change may play an indirect role in the genesis of CKDmfo. Currently, no scientific evidence supports any of these factors as the primary cause of CKDmfo, but many of these are likely to contribute to it.

Because hard water tightly binds with heavy metals, the bioavailability of heavy metals is lower in the presence of hard water. In complexes made of hard water, whether they are of heavy metals, fluoride, glyphosate, or some other compound, these materials become insoluble and precipitate, making them less likely to get into drinking water and so into humans. Nevertheless, as described above, hard water can cause renal stone disease in people who drink less water and are chronically dehydrated.

This scenario worsens if people routinely consume alcohol after a day of hard, outdoor work in hot climatic conditions. The presence of renal calculi (stones) in outdoor workers is not uncommon in all regions affected with CKDmfo. However, this is because of several common factors in both diseases, including exposure to harsh climatic conditions and frequent dehydration, both of which are common among the farmers (and outdoor workers) in these predominantly dry zonal villages.

Although the prevalence of renal stone disease is higher in the NCP, only a small percentage of people with renal stone disease experience renal failure. On the other hand, most people with CKDmfo do not have clinically relevant renal stone disease, which suggests that kidney stones have no role in the genesis of CKDmfo. Considering overall evidence, one can conclude that there is no direct connections between renal stone disease, glyphosate, heavy metals, or hard water with causing CKDmfo.

\section{It is not mandatory to add minerals to RO clean water}

Following membrane-based purification of water (such as RO or desalination), calcium and magnesium salts are added to drinking water. This is not because of any health reasons but in an attempt to improve the taste of the water because mineral-lesss water is tasteless. The addition of calculated amounts of calcium and magnesium salts, or others components to water after purification with a membrane technology or distillation will improves the taste; it is done purely to improve the taste for marketing purposes. There are no scientific or medical reasons to do so. Therefore, contrary to some belief, the addition of calcium and magnesium to water that is purified by RO technology is not a mandatory step before distributing the water for drinking purposes.

As explained, food provides approximately $95 \%$ of minerals and trace elements to humans. In addition, the efficiency of absorption of these elements from the intestine when they are derived from diet is superior to that when they are dissolved in drinking water. Most diets have higher-than-necessary amounts of calcium and magnesium. Moreover, only a portion of which is absorbed, leaving the excess calcium ions in the lumen of the gut. The latter binds to toxins (e.g., pesticide) preventing their absorption.

Food mixtures with excess minerals have the capacity to neutralize toxins and heavy metals in the intestine, making them unabsorbable complexes. This is also true for chemicals present in the environment, particularly those with phosphonic molecular structures such as glyphosate chelating these, and prevent their intestinal absorption. These ion-complexes are excreted with feces. Moreover, the unabsorbed dietary magnesium and calcium in the intestine is thought to prevent colonic cancer. 


\section{Discussion}

Older publications and information in some websites support the hypothesis that consumption of hard water is "associated" with the reduced risk of certain diseases. There are many unsubstantiated claims supporting the concept of association of both hard and soft water with human diseases. However, there is not a single, large, randomized control study that tested this hypothesis. All data presented are anecdotal or epidemiologic. However, most of the larger studies carried out in the recent past with regard to hardness or softness of water, do not show an association or causation with any known human disease.

Because more than $95 \%$ of the mineral intake of humans comes from food and not from drinking water, from a nutritional and physiological point of view, neither soft water nor hard water would have any impact on causing human diseases. If one drinks only soft water that may result in an approximate 5\% "mineral gap," which is quickly adjusted by homeostatic physiological processes controlled by the tight-knit hormonal systems in the body. Perhaps only valid arguments to have minerals in drinking water is to improve taste and minimize the corrosive effects of (pure) water.

The two hormones, $1,25(\mathrm{OH})_{2} \mathrm{D}$ and parathyroid hormone, quickly re-establish the mineral homeostasis by increasing the fractional absorption of minerals from the intestine and/or adjusting the mineral reabsorption from the renal tubules. Minerals in water thus, become important as "nutrition," only in those with extremely low mineral intakes: for example, those experiencing starvation (famine, hunger strike, extreme poverty, and extreme dehydration), prolonged major sicknesses, or disorders that interfere with the ability to eat and drink properly (e.g., anorexia nervosa), etc., but not in those who consume normal diets.

Contrary to the older literature, recent data indicate that there is no major difference in CVD or cancer incidences for those routinely drinking water containing low mineral contents (soft water, including drinking un-mineralized RO-purified water) or naturally occurring hard water. Previous misinterpretations may have been caused by sampling errors, methodological oversights, misguidance, and biased research hypotheses.

Because science and medical knowledge are constantly evolving, it is not surprising that our understanding and practices would also change with time. Science is eternally changing; what we believe today may be proven wrong tomorrow. One such example is the lack of a relationship between water ionic strength and hardness with human diseases. There is no doubt that the evolving knowledge base is applicable today and in fact, has a major influence on science and engineering, and our understanding of medicine. Our knowledge is constantly expanding and refining; thus, we need to be open mind and use the new knowledge we have today, to do the best for not only for today, but also for tomorrow.

\section{Conclusion}

There is no evidence to support that drinking hard water or soft water causes CKDmfo or other common diseases. Per historical documentation, hard water has been present in this CKDmfo-affected regions for centuries with little change. In the NCP, the most notable change in the domestic water constituents is fluoride. In certain villages, the level of fluoride in drinking water has significantly increased over the years. This is in part due to the large number of tube-wells introduced in the region to overcome the water scarcity. Many of these new sources, the water fluoride levels exceed $1.0 \mathrm{mg} / \mathrm{L}$. This is well above the safe upper limits of fluoride in drinking water (currently $0.6 \mathrm{mg} / \mathrm{L}$ ), that is recommended by the WHO and Environmental Protection Agency of United States.

While, more than $80 \%$ of the inhabitants in NCP consume water from dug-wells, where water is thought to be contaminated (e.g., agrochemicals), no such contamination is expected or observed in groundwater obtained via deep tube wells $[44,78]$. However, people drinking from both shallow wells and tube wells, both get this fatal disease. Nevertheless, the latter has more hardness and higher contents of fluoride. Whether interactions of fluoride with something else other than hard water or as-yet-unknown interactions with other chemicals contributing to the development of CKDmfo is not known.

In the absence of credible scientific data, we conclude that neither the softness nor hardness of water causes chronic human diseases such as CKDmfo, CVD, etc.(with the exception of renal stone disease). None of the hypotheses put forward have been properly tested scientifically yet, explain why CKDmfo has manifested only in a geographically demarcated regions (and the current spread of the disease outside the NCP) during the past 2 to 3 decades, or the escalating incidence of the disease. Overall, the data do not support the view that consumption of hardwater, softwater, water salinity (or ionicity), agrochemicals, phosphate in drinking water causes or contributes to any known renal disease (except renal stones), including CKDmfo in Sri Lanka.

Acknowledgements: I am grateful for the constructive suggestions made by Professors Stanley Weeraratne and Oliver Ileperuma in an earlier version of this manuscript.

Conflicts of Interest: The author has no conflicts of interest. There is no funding associated with this manuscript.

\section{References}

1. WHO. Food safety issues associated with products from aquaculture. Report of a joint FAO/NACA/WHO Study Group. (1999) World Health Organ Tech Rep Ser 883: i-vii, 1-55.

2. Wimalawansa, S.J. Olcott Oration-2013.

3. Pocock, S.J., Shaper, A.G, Cook, D.G., et al. British Regional Heart Study: geographic variations in cardiovascular mortality, and the role of 
water quality. (1980) Br Med J 280(6226): 1243-1249.

4. Nerbrand, C., Svardsudd, K., Ek, J., et al. Cardiovascular mortality and morbidity in seven counties in Sweden in relation to water hardness and geological settings. The project: myocardial infarction in mid-Sweden. (1992) Eur Heart J 13(6): 721-727.

5. Hara, N., Sakata, K., Nagai, M., et al. Statistical analyses on the pattern of food consumption and digestive-tract cancers in Japan. (1984) Nutr Cancer 6(4): 220-228.

6. Stocks, P. Incidence of congenital malformations in the regions of England and Wales. (1970) Br J Prev Soc Med 24(2): 67-77.

7. Hewitt, D. Geographical variations in the mortality attributed to spina bifida and other congenital malformations. (1963) Br J Prev Soc Med 17(1): 13-22.

8. UNICEF/WHO. Progress on Drinking Water and Sanitation: Joint Monitoring Programme - Special Focus on Sanitation. (2008) WHO.

9. Wimalawansa, S.J. Escalating Chronic Kidney Diseases in Sri Lanka: Causes, Solutions and recommendations. (2014) Environ Health Prev Med 19(6): 375-394.

10. Heyden, S. The hard facts behind the hard-water theory and ischemic heart disease. (1976) J Chronic Dis 29(3): 149-157.

11. Hall, P., Jungner, I. Hard drinking water and ischemic heart disease: calcium, bloodlipids, and acute myocardial infarcts. (1993) J Med Syst 17(3-4): 277-281.

12. Crawford, T., Crawford, M.D. Prevalence and pathological changes of ischaemic heart-disease in a hard-water and in a soft-water area. (1967) Lancet 1(7484): 229-232.

13. Malpas, P., Lloyd, S., Lowe, C.R., et al. Cardiovascular disease in hard and soft water areas. (1973) Lancet 301(7798): 321.

14. Stitt, F.W., Clayton, D.G., Crawford, M.D., et al. Clinical and biochemical indicators of cardiovascular disease among men living in hard and soft water areas. (1973) Lancet 1(7795): 122-126.

15. Morris, R.W., Walker, M., Lennon, L.T., et al. Hard drinking water does not protect against cardiovascular disease: new evidence from the British Regional Heart Study. (2008) Eur J Cardiovasc Prev Rehabil 15(2): 185-189.

16. Lewis, P.G. The Influence of Calcareous (Hard) Drinking Water in Health and Disease. (1911) Proc R Soc Med 4(Balneol Climatol Sect): 119-128.

17. Masironi, R., Pisa, Z., Clayton, D. Myocardial infarction and water hardness in the WHO myocardial infarction registry network. (1979) Bull World Health Organ 57(2): 291-299.

18. Leoni, V., Fabiani, L., Ticchiarelli, L. Water hardness and cardiovascular mortality rate in Abruzzo, Italy. (1985) Arch Environ Health 40(5): 274-278.

19. Mackinnon, A.U., Taylor, S.H. Relationship between 'sudden' coronary deaths and drinking water hardness in five Yorkshire cities and towns. (1980) Int J Epidemiol 9(3): 247-249.

20. Sonneborn, M., Mandelkow, J. German studies on health effects of inorganic drinking water constituents. (1981) Sci Total Environ 18: 47-60.

21. Wimalawansa, S.J. Vitamin D in the new millennium. (2012) Curr Osteoporos Rep 10(1): 4-15.

22. Wimalawansa, S.J. Vitamin D: An essential component for skeletal health. (2012) Ann N YAcad Sci 1240: E1-12.

23. Prepas, E.E., Pinel-Alloul, B., Chambers, P.A., et al. Lime treatment and its effects on the chemistry and biota of hardwater eutrophic lakes. (2001) Fresh water Biol 46(8): 1049-1060.

24. WHO. Guidelines for drinking water quantity. (1983) World Health Organization, Geneva.

25. Galan, P., Arnaud, M.J., Czernichow, S., et al. Contribution of mineral waters to dietary calcium and magnesium intake in a French adult population. (2002) J Am Diet Assoc 102(11): 1658-1662.

26. Wimalawansa, S.J. Vitamin D: Everything You Need to Know (Nutrition and Vitamin D). (2012) Karunaratne \& Sons.

27. Luoma, H., Aromaa, A., Helminen, S., et al. Risk of myocardial infarction in Finnish men in relation to fluoride, magnesium and cal- cium concentration in drinking water. (1983) Acta Med Scand 213(3): 171-176.

28. Yang, C.Y. Calcium and magnesium in drinking water and risk of death from cerebrovascular disease. (1998) Stroke 29(2): 411-414.

29. Joffres, M.R., Reed, D.M., Yano, K. Relationship of magnesium intake and other dietary factors to blood pressure: the Honolulu heart study. (1987) Am J Clin Nutr 45(2): 469-475.

30. Kesteloot, H., Joossens, J.V. Relationship of dietary sodium, potassium, calcium, and magnesium with blood pressure. Belgian Interuniversity Research on Nutrition and Health. (1988) Hypertension 12(6): 594-599.

31. Itoh, K., Kawasaki, T., Uezono, K. Relationship of dietary intake of sodium, potassium, calcium and magnesium to blood pressure. (1995) Nihon Koshu Eisei Zasshi 42(2): 95-103.

32. Wimalawansa, S.J. Antihypertensive effects of oral calcium supplementation may be mediated through the potent vasodilator CGRP. (1993) Am J Hypertens 6(12): 996-1002.

33. Appelman, H.D., McLaughlin, J.K., Blot, W.J., et al. A cohort study of stomach cancer in a high-risk American population. (1992) Cancer 69(11): 2867-2868.

34. Thouez, J.P., Ghadirian, P., Petitclerc, C., et al. International comparisons of nutrition and mortality from cancers of the oesophagus, stomach and pancreas. (1990) Geogr Med 20: 39-50.

35. Song, C.H., Barrett-Connor, E., Chung, J.H., et al. Associations of calcium and magnesium in serum and hair with bone mineral density in premenopausal women. (2007) Biol Trace Elem Res 118(1): 1-9.

36. Tranquilli, A.L., Lucino, E., Garzetti, G.G., et al. Calcium, phosphorus and magnesium intakes correlate with bone mineral content in postmenopausal women. (1994) Gynecol Endocrinol 8(1): 55-58.

37. Costi, D., Calcaterra, P.G., Iori, N., et al. Importance of bioavailable calcium drinking water for the maintenance of bone mass in post-menopausal women. (1999) J Endocrinol Invest 22(11): 852-856.

38. Aptel, I., Cance-Rouzaud, A., Grandjean, H. Association between calcium ingested from drinking water and femoral bone density in elderly women: evidence from the EPIDOS cohort. (1999) J Bone Miner Res 14(5): 829-833.

39. Bellizzi, V., De Nicola, L., Minutolo, R., et al. Effects of water hardness on urinary risk factors for kidney stones in patients with idiopathic nephrolithiasis. (1999) Nephron 81(Suppl 1): 66-70.

40. Wickremasinghe, A.R., Peiris-John, R.J., Wanigasuriya, K.P. Chronic kidney disease of unknown aetiology in the North Central Province of Sri Lanka: trying to unravel the mystery. (2011) Ceylon Med J 56(4): 143-146.

41. Jayathilaka, N.M.P., Mendis, S., Mehta, F.R., et al. WHO Sri Lanka CKDu report: Chronic kidney disease of unknown aetiology (CKDu): a new threat to health. (2013) WHO-CKDu-Final Report.

42. Jayatilake, N., Mendis, S., Maheepala, P., et al. Chronic kidney disease of uncertain aetiology: prevalence and causative factors in a developing country. (2013) BMC Nephrol 14(1):180.

43. Wimalawansa, S.A., Wimalawansa, S.J. Escalating incidence of chronic kidney disease of multi-factorial-origin (CKD-mfo) in Sri Lan$\mathrm{ka}$ and its long-term consequences. (2014) Scandinavian Journal of Work, Environment \& Health. ( submitted).

44. Wimalawansa, S.J. The role of ions, heavy metals, fluoride, and agrochemicals: Critical evaluation of potential aetiological factors of chronic kidney disease of multifactorial origin (CKDmfo/CKDu) and recommendations for its eradication. (2015) Environ Geochem Health $1-40$.

45. Myers, G.L., Miller, W.G., Coresh, J., et al. Recommendations for improving serum creatinine measurement: a report from the Laboratory Working Group of the National Kidney Disease Education Program. (2006) Clin Chem 52(1): 5-18.

46. Lamb, E.J., Levey, A.S., Stevens, P.E. The Kidney Disease Improving Global Outcomes (KDIGO) guideline update for chronic kidney disease: evolution not revolution. (2013) Clin Chem 59(3): 462-465.

47. National Kidney Foundation. K/DOQI clinical practice guidelines 
for chronic kidney disease: evaluation, classification, and stratification. (2002) Am J Kidney Dis 39(2 Suppl 1): S1-266.

48. Cockcroft, D.W., Gault, M.H. Prediction of creatinine clearance from serum creatinine. (1976) Nephron 16(1): 31-41.

49. Levey, A.S., Coresh, J., Greene, T., et al. Using standardized serum creatinine values in the modification of diet in renal disease study equation for estimating glomerular filtration rate. (2006) Ann Intern Med 145(4): 247-254.

50. Inker, L.A., Schmid, C.H., Tighiouart, H., et al. Estimating glomerular filtration rate from serum creatinine and cystatin C. (2012) N Engl J Med 367(1):20-29.

51. Higgins, R. CKD: Keeping kidneys health: Your essential reference for the diagnosis and management of chronic kidney disease. (2009) Ed: Taylor, C. Class Publishing Ltd 1-97.

52. Wyne, K.L., Wimalawansa, S.J. Screening and Diagnosis of Chronic Tubular Kidney Disease of Multi-Factorial Origin, 5th International Conference on Sustainable Built Environment. (2014) Kandy, Sri Lanka 1: 234-243.

53. Wanigasuriya, K. Update on uncertain etiology of chronic kidney disease in Sri Lanka's north-central dry zone. (2014) MEDICC Rev 16(2): 61-65.

54. Nanayakkara, S., Senevirathna, S.T., Karunaratne, U., et al. Evidence of tubular damage in the very early stage of chronic kidney disease of uncertain etiology in the North Central Province of Sri Lanka: a cross-sectional study. (2012) Environ Health Prev Med 17(2): 109-117. 55. Chandrajith, R., Nanayakkara, S., Itai, K., et al. Chronic kidney diseases of uncertain etiology (CKDue) in Sri Lanka: geographic distribution and environmental implications. (2011) Environ Geochem Health 33(3): 267-278.

56. Jayasekera, J., Dissnayake, D.M., Ratnayake, P., et al. The effect of concentrated water on reservoirs of high prevalence areas on CKD of unknown origin in Sri Lanka on mice. (2012) Colombo, Sri Lanka: Sri Lanka Medical Association Annual Scientific Sessions, 2012.

57. Dharma-Wardana, M.W., Amarasiri, S.L., Dharmawardene, N., et al. Chronic kidney disease of unknown aetiology and ground-water ionicity: study based on Sri Lanka. (2014) Environ Geochem Health 37(2): 221-231.

58. Jayasumana, C., Gunatilake, S., Siribaddana, S. Simultaneous exposure to multiple heavy metals and glyphosate may contribute to Sri Lankan agricultural nephropathy. (2015) BMC Nephrol 16:103.

59. Jayasumana, C., Gunatilake, S., Senanayake, P. Glyphosate, hardwater and nephrotoxic metals: are they the culprits behind the epidemic of chronic kidney disease of unknown etiology in sri lanka? (2014) Int J Environ Res Public Health 11(2): 2125-2147.

60. Wimalawansa, S.A., Wimalawansa, S.J. Agrochemical-Related Environmental Pollution: Effects on Human Health. (2014) GJBAHS 3(3): $72-83$.

61. Wimalawansa, S., Wimalawansa, S.J. Protection of watersheds, control and responsible use of fertiliser to prevent phosphate eutrophication of reservoirs in Sri Lanka. (2015) Int J Res Environ Sci 1(2): $1-18$.

62. Hofmeiste, F. (1888) Arch Exp Pathol Pharmacol 24: 247-260.

63. Yang, Z. Hofmeister effects: an explanation for the impact of ionic liquids on biocatalysis. (2009) J Biotechnol 144(1): 12-22.

64. Xiong, X., Liu, J., He, W., et al. Dose-effect relationship between drinking water fluoride levels and damage to liver and kidney functions in children. (2007) Environ Res 103(1): 112-116.
65. Levine, R., Hirayama, B., Wright, E.M. Sensitivity of renal brush-border Na+-cotransport systems to anions. (1984) Biochim Biophys Acta 769(2): 508-510.

66. Barbier, O., Arreola-Mendoza, L., Del Razo, L.M. Molecular mechanisms of fluoride toxicity. (2010) Chem Biol Interact 188(2): 319-333. 67. Agalakova, N.I., Gusev, G.P. Fluoride-induced death of rat erythrocytes in vitro. (2011) Toxicol In Vitro 25(8):1609-1618.

68. Ritter, L., Solomon, K., Sibley, P., et al. Sources, pathways, and relative risks of contaminants in surface water and groundwater: a perspective prepared for the Walkerton inquiry. (2002) J Toxicol Environ Health A 65(1): 1-142.

69. Eberlein, K. Risk of anthropogenic nitrogen and phosphorus entry into the North Sea ecosystem. (1994) International journal of hygiene and environmental medicine 196(4): 285-311.

70. Alcazar Arroyo, R. Electrolyte and acid-base balance disorders in advanced chronic kidney disease. (2008) Nefrologia 28(Suppl 3): 8793.

71. Wimalawansa, S., Wimalawansa, S.J. Water pollution associated occupational diseases: Special emphasis on chronic kidney disease of multifactorial origin (CKDmfo/CKDu). (2014) Jacob J Environ Sci (submitted).

72. Wimalawansa, S.J. Agrochemicals and chronic kidney disease of multifactorial origin: An Environmentally induced occupational exposure disease. (2015) Int J Nephrol Kidney Failure 1(3): 1-9.

73. Wimalawansa, S.A., Wimalawansa, S.J. Impact of changing agricultural practices on human health: Chronic kidney disease of multi-factorial origin in Sri Lanka. (2014) Wudpecker Journal of Agricultural Research 3(5): 110-124.

74. Conley, D.J., Paerl, H.W., Howarth, R.W., et al. Ecology Controlling eutrophication: nitrogen and phosphorus. (2009) Science 323(5917): 1014-1015.

75. Correll, D.L. The role of phosphorus in the eutrophication of receiving waters: A Review. (1998) J Environ Qual 27: 261-266.

76. Dharmawardana, M.W., Amarasiri, S.L., Dharmawardene, N., et al. Chronic kidney disease of unknown aetiology and ground-water ionicity: study based on Sri Lanka. (2014) Environ Geochem Health 37(2): 221-231.

77. Dharmaratne, R.W. Fluoride in drinking water and diet: the causative factor of chronic kidney diseases in the North Central Province of Sri Lanka. (2015) Environ Health Prev Medicine 20(4): 237-242.

78. Wimalawansa, S.J, editor Prevention of CKD of multi-factorial Origin (CKD-mfo): Issues, gravity, \& the importance of early diagnosis. $5^{\text {th }}$ International Conference on Sustainable Built Environment. (2014) "Environment pollution of prevention of CKD-mfo in Sri Lanka: ICSBE.

79. Wimalawansa, S.J. Escalating chronic kidney diseases of multi-factorial origin (CKD-mfo) in Sri Lanka: causes, solutions, and recommendations-update and responses. (2015) Environ Health Prev Med 20(2): 152-157.

80. DOA. Agricultural Phosphorus and Eutrophication, Second Edition. (2003) Agriculture Research Service; 43.

81. Wimalawansa, S.J. Purification of contaminated water with reverse osmosis: Effective solution of providing clean water for human needs in developing countries. (2013) IJETAE 3(12): 75-89.

82. Dissanayake, C.B., Chandrajith, R. Medical geology in tropical countries with special reference to Sri Lanka. (2007) Environ Geochem Health 29(2): 155-162.

83. Dissanayake, C.B. Water quality and dental health in the Dry Zone of Sri Lanka. (1996) Geological Society, London, Special Publications 113(1): 131-140.

Journal ISSN: 2378-6841

E-mail: environmentalscience@ommegaonline.org

Website: www.ommegaonline.org
Journal Title: Journal of Environment and Health Science (JEHS)

Journal Short Name: J Environ Health Sci 